\title{
Validation information
}

When required we performed Sanger-based sequencing on PCR-amplified genomic DNA fragments to confirm sequence variations identified by next generation sequencing. 